\title{
Institutional Research Culture Scale (IRCS): Development and Validation in the context of Universities in Kerala, India
}

\author{
${ }^{1 *}$ Jayapraveen Jayachandran \& ${ }^{2}$ Divya Chandrasenan \\ ${ }^{1}$ ICSSR Doctoral Scholar, University of Kerala, Thiruvananthapuram, Kerala, India \\ ${ }^{2}$ Assistant Professor, University of Kerala, Thiruvananthapuram, Kerala, India \\ *Corresponding author
}

\begin{abstract}
Research Culture encompasses the behaviour, values, expectations, attitudes, and norms of our research communities. It influences researchers' career paths and determines the way that research is conducted and communicated. However, the term research culture remains ambiguous (Hill, 1999) and the tool to assess the research culture is very little and a resurgence is need in the field. The intent of the study is to comprehend the term research culture in the institutions in Kerala, India by developing a scale and validate it. Population of the study comprised of all the faculty members in the universities in Kerala. Sample was selected through multistage cluster sampling technique (Creswell, 2011). Out of the seventeen state universities five mainstream multidisciplinary universities were selected for the study. Four hundred faculty members were finally chosen as sample and the obscure and abstruse samples were avoided. Exploratory factor analysis is used to extract five factors which is quite evolved from the theoretical concepts (Clemena \& Acosta, 2007) that intensify the research culture in the institutions. When interpreted, these factors align well with the theories that referred for the study. The results of the study indicated that the dimensions such as, Institutional Culture, Working Conditions, Research Infrastructure, Research Collaboration and Sharing, Institutional Research Policy and Agenda and Research Monitoring and Mentoring were perceived as relatively more influential for promotion of research culture and selected as the major factors for the preparation of the tool.
\end{abstract}

Key Words: Institutional Research Culture, Research Culture Scale, Higher Education, Research Monitoring.

\section{Introduction}

The acquisition of knowledge is the mission of research, the transmission of knowledge is the mission of teaching, and the application of knowledge is the mission of public service (Perkins, 1988). In the emerging Indian society, knowledge creation, exchange, networking, and maximum utilization have become most vital for the advancement of the nation. An excellent research is a prerequisite to economic development in the knowledge society. It is the creation of new knowledge and the use of existing knowledge in a new way to generate new concepts, 


\section{International Conference on Research in}

\section{BEHAVIORAL \& SOCIAL SCIENCES}

July $23-25,2021$

Stockholm, Sweden

methodologies, and understandings. In India, the question of quality of research has emerged due to enormous growth of research which is produced mainly as a part of doctoral research $\mathrm{Ph} . \mathrm{D}$. in the University system during the last few decades. The growth in numbers and the subsequent issues of the quality of research output call for a comprehensive review of the existing situation and to suggest corrective measures to be taken to improve the state of research in India. There is a consensus that bar a few exceptions, the overall quality of University and College level research in India is far from satisfactory. Indeed, in many institutions the quality of research is alarmingly poor. In large number of cases theses do not conform to international standards and do not make significant contributions to theoretical or applied aspects of a given discipline (UGC Report, 2019). It has become a sort of self-gratifying academic rituals needed to be done for requirements mostly that come not from within. Many researchers see research as a means of livelihood. In such cases, it is research that ultimately suffers. Therefore, the research activities in the cultural perspective are dynamic and may change from time to time.

According to the UGC, out of the total enrolment of students in universities and colleges in India during the academic year 2011-12, about 86 per cent were enrolled for undergraduate courses and 12.2 per cent for post graduate courses while only 0.79 per cent of the total students had registered for research. The number of research scholars, particularly in the field of scientific and technological research is far less than the requirement of the country (University Grants Commission, 2012). The number and quality of Ph.Ds. produced by the Indian universities are less compared to the leading universities in the world. During 2010-11, various Indian universities altogether had awarded 16,093 Ph.D. degrees of which $5037 \mathrm{Ph} . \mathrm{Ds}$. (31.3 per cent) were in the faculty of Arts. While 10.5 per cent (1682) of the total Ph.D. degrees awarded were in the faculty of Engineering and Technology, it was only 3.7 per cent (601) in Medicine, 7.8 per cent (1259) in Commerce \& Management, 4.7 per cent (751) in Agriculture \& Veterinary Science, 4 per cent (645) in Education and 1.4 per cent (220) of the total in the faculty of Law during the same period (University Grants Commission, 2012).

\subsection{Higher Education System}

Among the several states in India, Kerala occupies an enviable position in several indicators of social and human development. Kerala ranks well in comparison with some of the advanced countries of the world in terms of human development. It stands as the most literate state and as a state that provides elementary education to all the eligible children. Kerala's education performance has been so impressive that it could receive the distinctive acclamation as the 'Kerala model'; and some recommend 'Keralization' of the whole education system in India (Lewis,1997). Ashok Mitra Commission on Kerala Education (1999) has the impression that higher education in the state has expanded well, where it observed, "the higher education system in Kerala has extensive reach". It added that 10 per cent of those who enter primary school enrol for degree courses; and, that the total number of students entering higher education every year accounts for about 15 per cent of the relevant age group. Inequalities in higher education are also much lower in Kerala compared to other states of India. With respect to performance in terms of enrolment ratios by gender and caste groups, Kerala stands the first. The gross enrolment ratio among women, scheduled castes and scheduled tribes is higher than 


\section{International Conference on Research in}

\section{BEHAVIORAL \& SOCIAL SCIENCES}

July $23-25,2021$

Stockholm, Sweden

the ratio in India as a whole. Even pupil-teacher ratios in higher education in Kerala are highly favourable, compared to the all-India scenario (MHRD, 2018)

Currently, there are nineteen universities in Kerala which include one central university, sixteen state universities and two deemed universities. Considering the statistics, for every, one lakh population on average, there are only 80 institutions of higher education, including universities and colleges in Kerala, while the corresponding number is 99 at the all-India level. Thus 'degree of availability of higher education institutions' has always been less in Kerala than the national average. In short, Kerala's higher education system has not expanded as much as one expects in a state where elementary education is nearly universal and secondary education has expanded reasonably well (Ministry of Human Resources and Development, 2011). The Perspective Plan 2030 of Kerala, also known as Vision 2030 has underscored the importance of higher education in the development of the Kerala economy to reach a growth rate of 7.5 per cent. It states that 50 per cent of all young people shall complete a higher education programme by 2025 . Accounting for 50 per cent of India's exports in education service by 2030, it is expected that with "global knowledge cities" in Kerala, the state will be a key node to global knowledge network by 2030. It will be in the league of the top ranked countries in terms of efficiency, competitiveness, services, and market delivery in education. While these goals are laudable, the strategies that Kerala adopts to reach these goals need to be carefully formulated (Draft Report of Kerala Perspective Plan, 2014).

To improve the quality and quantity of relevant and meaningful research, a proper research culture should be enhanced. Linkages and collaborations between higher education institutions and premier research centres and between universities and industries inside and abroad also should be promoted. The state has built up a strong education system that promotes research in both quantity and quality wise. A well-established research culture is an essential one for the institutions to maintain a sustainable research environment and for the improvement of its quality. Kerala can expect to be a global knowledge power only if the state succeeds in strengthening its research culture and the ability to carry out quality research in every discipline. The University Grants Commission Report (2019) suggests various plans to enhance the research culture of the institutions such as faculty recruitment, more post-doctoral fellowships, and travel grant for researchers.

\subsection{Research culture}

Research culture can be positively understood as a form of basic assumptions about the creation, discovery, and development of knowledge through research activities by certain groups that can be passed down and taught to the next generation. It is knowledge about the process of research that refers to the value which consists of the beliefs, assumptions and principles are supported by rules as a norm that implemented in the form of behavioural research. The higher education system, within which Indian University System operates, is marked by regional, socio-cultural, linguistic and institutions related structural diversities. Given these diversities, the strengthening of research culture in Indian higher education requires multi-pronged activities beginning with a bottom-up than a top-down, "one-size-fitsall" approach to introduce a culture of research which is anchored in robust classroom 


\section{International Conference on Research in}

\section{BEHAVIORAL \& SOCIAL SCIENCES}

July $23-25,2021$

Stockholm, Sweden

pedagogy and curricula designed to arouse intellectual curiosity and its appropriate channelization and imparting of research tools and techniques to ensure that it eventually reaches fruition.

Research culture encompasses the behaviours, values, expectations, attitudes, and norms of our research communities. It influences researchers' career paths and determines the way that research is conducted and communicated. Research culture deals with the creation, discovery, and development of knowledge through various research activities. The knowledge accumulated through research can be passed down and taught to the next generation. Research culture is a vast concept, which includes the way we evaluate, support and reward quality in research, how we recognise varied contributions to a research activity, and the way we support different career paths. Establishment of a research culture cannot only be seen on one side because every educational institution has a different academic environment, so it requires a different approach to suit the environmental conditions of an educational institution. Research culture can be understood and viewed as an approach that has four distinct phases in the process of any environmental conditions, namely (i) creating a research culture, (ii) growing a research culture, (iii) developing a cultural research, (iv) nurturing a research culture. Hazelcorn (2005) reminds us that building a research culture 'is not without its challenges, especially in those institutions where research is relatively new or fragile.' She points out that it is 'not a one-off project but rather the result of an on-going series of strategic policies and actions.

\subsection{Institutional Research Culture}

Barett (2010) says "Quality in higher education demands the establishment of an institutional culture, not so much a matter of total quality management but rather one of total quality care, in which each professional is seized of his or her responsibilities and takes care over all his or her own professional efforts". Successful institutions provide significant support to faculty research efforts. They can choose from a variety of tactics to develop a culture of research and increase faculty research productivity. Hanover-Research (2014) identifies influential factors behind the development of a culture of research, based on a review of secondary literature and institutional practices. Research- cantered institutions provide supports which include effective leadership and clear goals, faculty training and support programmes and research centres.

The institutional research culture within an institution is the knowledge about research topics and processes which are sanctioned as appropriate and relevant; the values, beliefs, attitudes, and norms which surround the research process within the institution, and the various material ways in which the institution supports or denies support to its researching individuals and groups. New values, beliefs and norms about research develop as individuals and groups attempt to carry out research projects and to "push the boundaries" of what the institution has previously approved.

Mortimore (2000) proposed activity theory that provides a philosophical framework to the institutional research culture. The assumption is that research culture is the product of the activities that occur in a socio-historical and socio-cultural context and the activity itself changes because of our interactions with the context and our consciousness about those actions. 


\section{International Conference on Research in}

\section{BEHAVIORAL \& SOCIAL SCIENCES}

July $23-25,2021$

Stockholm, Sweden

The research related with the influence of developing research culture is vital for the legitimacy of the field. An activity system has a purpose which leads to an outcome and is based in a context. Depending on the case it is possible to emphasise different parts of the system, such as the subject-mediating tool-object triad, where the focus might be on the tools themselves (choice of research method) and their mediating function, or the subject-community-object triad, where the influence of the community might be the focal point. In the case of research culture, it has proved valuable to consider the ways in which the tools-rules-roles triad mediate the research activity. It is also necessary to remember that activities are made up of actions, which in turn are made up of operations. There can also be several layers of activity from the actual act of carrying out research, such as planning, taking, transcribing, and analysing an interview, to the management of research at a national level, for example by policymaking or budget-making.

None of the components should ever be considered in isolation nor deemed stable in time or place; an activity system is always dynamic. Part of the power of the theory lies in the consideration of the way that the subject changes the task, and the way that other parts of the system influence the nature of the change. It focuses on the activities mediated in the immediate environment and that it is useful and necessary to place these activities in a broader context, which can operate at several levels.

\section{Conceptual and Empirical Literature on Institutional Research Culture}

The concept of institutional research culture is deeply rooted on the theory of Clemena and Acosta Model (2007). The theory understands the research culture from the perspective of faculty and how this affects the productivity of the faculty in higher education institutions. It has been focussed on the dynamics of the interrelation between three domains (Clemena and Acosta, 2007). The first domain, i.e., the Trifocal Function, comprises the university faculty's trifocal task of teaching, research, and community service or extension. These tasks interact in different ways for each faculty member. The second domain, the Individual Attributes and Policies, refers to the knowledge, skills, values, and attitudes that the faculty members possess relative to the conduct of research. This also includes their readiness, capacity, and experience with regards to research. The third domain, the Institutional Attributes and Policies, refers to the policies set by the institution for the purpose of developing the research activities.

Clemena and Acosta Model also suggest various indicators to assess the research culture of the institutions. The indicators are Institutional research policies and agenda, Departmental culture and working, Working conditions, Budget for research, Infrastructure, Collaboration with and access to research professionals in other institutions, Policies and guidelines on research benefits and incentives, Research committee and Publications. Thus, this model might be relevant for describing institutional research culture in academic departments/universities and its impact on faculty productivity. From the review of related literature, it is identified that institutional research culture is an essential one for the development and progress of higher education institutions. Institutional research culture has been the topic of concern for many universities' research administrators, especially new or budding universities which are interested in having, growing, nurturing a research culture. So, a tool is quintessential for assessing the research culture of institutions and validating it for the universities in Kerala. 


\section{International Conference on Research in \\ BEHAVIORAL \& SOCIAL SCIENCES}

July $23-25,2021$

Stockholm, Sweden

\section{Method}

\subsection{Construction of the Institutional Research Culture Scale}

Normative Survey is used to assess the Research Culture of the institutions. The investigators constructed items for the Institutional Research Culture Scale by referring the theory of Clemena and Acosta Model (2007). The five major components related with Institutional Research Culture were considered based on this theoretical background. The components considered were Working conditions, Research Infrastructure, Research collaboration and sharing, Research mentoring and monitoring and Institutional policies and agenda (Clemena \& Acosta, 2007). After the consideration of components and with the help of reviewing literature, the investigators framed a scale of 40 items. Later the ambiguous, repetitive, and indirect items were removed, it is reduced to 28 items. The investigators follow 5-point Likert type response format ( 1 = Strongly disagree, $5=$ Strongly Agree) as Kahn and Miller (2000), higher scores indicate higher levels of research culture in institutions.

\subsection{Procedure}

Using the cluster sampling technique, the investigators selected 5 major state universities in Kerala, India, excluding the Central, Open, Deemed, Technical and Professional Universities. Those universities which provide multi-disciplinary discipline were selected for the study. The selected universities are University of Kerala, Mahatma Gandhi University, Cochin University of Science and Technology (CUSAT), University of Calicut and Kannur University. The teaching departments of these state universities were selected as the Trifocal function is predominant there. It comprises the university faculty's trifocal task of Teaching, Research, and Community service or Extension function and a major criterion that results in institutional research culture (Clemena \& Acosta, 2007). The rating scale was administered among 400 university faculties from all the teaching departments of these 5 state universities in Kerala. The scale was implemented among the adequate sample group. The data collected was subjected to principal component factor analysis by using SPSS16.

\subsection{Participants}

Out of 426 teachers who opened the survey, 26 were removed due to more than $50 \%$ missing data which leads to ambiguous results, leaving the $N$ of 400 . The distribution is given in Table 1 .

Table 1: Sample Distribution

\begin{tabular}{lll}
\hline Sl. No & Name of the University & $N$ \\
\hline 1 & University of Kerala & 170 \\
\hline 2 & Mahatma Gandhi University & 69 \\
\hline 3 & $\begin{array}{l}\text { Cochin University of Science and Technology } \\
\text { (CUSAT) }\end{array}$ & 50 \\
\hline 4 & University of Calicut & 71 \\
\hline 5 & Kannur University & 40 \\
\hline Total & & 400 \\
\hline
\end{tabular}




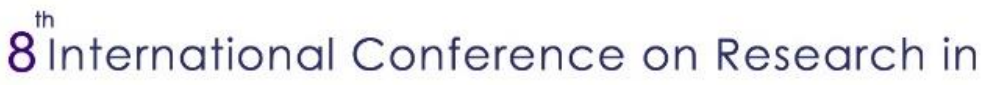 \\ BEHAVIORAL \& SOCIAL SCIENCES}

July $23-25,2021$

Stockholm, Sweden

\subsection{Measures}

The participants completed the Institutional Research Culture Scale, which should be analysed. The tool consists of 27 items to complete the study and disseminate findings. Respondents indicate their responses by using 5-point Likert Scale. High scores indicate higher levels of institutional research culture. Participants also completed the data about their qualification, designation, concerned departments and university. The IRCS has high internal reliability (Cronbach's $\alpha \geq .78$ ) and adequate construct validity (Creswell, 2011). For this sample, the IRCS had a Cronbach's alpha of 0.78 .

\section{RESULTS}

The sampling adequacy test was performed through Kaiser-Meyer-Olkin (KMO) statistic. The data were assessed through factor analysis. Table 2 and 3 summarized the KMO value and extraction of components through the factor analysis, respectively.

Table 2 shows the KMO value of Institutional Research Culture Scale. Since, KMO values are greater than 0.6, it is adequate, Kaiser and Rice (1974). Therefore, the Kaiser-Meyer-Olkin measure of sampling adequacy with value of 0.659 was acceptable. Barlett's Test of Sphericity significant $(\chi 2=9.790, \mathrm{df}=378, \mathrm{p}<.001)$ shows that the values are significant and hence, acceptable, implying that non-zero correlations existed at the significance level of 0.000 , it provided an adequate basis for proceeding with the factor analysis. These results suggested the data were suitable to proceed with the EFA (Hair, Black, Babin., \& Anderson, 2010; Mvududu., \& Sink, 2013).

Table 2: KNO value and Bartlett's Test of sphericity

\begin{tabular}{lll} 
Kaiser-Meyer-Olkin Measure of Sampling Adequacy & .659 \\
\cline { 2 - 3 } Bartlett's Test of sphericity & Approx. Chi-Square & 9.790 \\
\cline { 2 - 3 } & Df & 378 \\
\cline { 2 - 3 } & Sig. & .000 \\
\hline
\end{tabular}

According to table 3, it is evident that the IRCS is based on five components. The five factors were distributed as factor 1 (Working Conditions), Factor 2 (Research Collaboration and Sharing), Factor 3 (Research Infrastructure), Factor 4 (Institutional Research Policy and Agenda) and Factor 5 (Research Monitoring and Mentoring).

Table 3: Factor Loading for the IRC Scale 28 items

\begin{tabular}{clccccc}
\hline Q.No. & Items & \multicolumn{5}{c}{ Components } \\
\hline & Factor I & $\begin{array}{c}\text { Factor } \\
\text { II }\end{array}$ & $\begin{array}{c}\text { Factor } \\
\text { III }\end{array}$ & $\begin{array}{c}\text { Factor } \\
\text { IV }\end{array}$ & $\begin{array}{c}\text { Factor } \\
\text { V }\end{array}$ \\
\hline 22 & $\begin{array}{l}\text { The institution fosters a strong } \\
\text { personal and professional relationship } \\
\text { among researchers. }\end{array}$ & $\mathbf{. 8 3 3}$ & & & & \\
\hline 19 & $\begin{array}{l}\text { Institution encourages both the faculty } \\
\text { and researchers to participate in both }\end{array}$ & $\mathbf{. 8 1 8}$ & & & \\
\end{tabular}




\section{$8^{\text {th }}$ International Conference on Research in \\ BEHAVIORAL \& SOCIAL SCIENCES}

July $23-25,2021$

Stockholm, Sweden

\begin{tabular}{|c|c|c|c|c|c|}
\hline & $\begin{array}{l}\text { regional and national research } \\
\text { programmes. }\end{array}$ & & & & \\
\hline 20 & $\begin{array}{l}\text { Institution offers expert talks on } \\
\text { research methodology frequently. }\end{array}$ & .725 & & & \\
\hline 24 & $\begin{array}{l}\text { Institution recognises the faculty with } \\
\text { excellent research skills annually. }\end{array}$ & .786 & & & \\
\hline 27 & $\begin{array}{l}\text { The institution encourages faculty to } \\
\text { conduct externally funded research. }\end{array}$ & .679 & .423 & & \\
\hline 18 & $\begin{array}{l}\text { The institution gives opportunity to } \\
\text { faculty to convene seminars/ } \\
\text { workshops related with their own } \\
\text { research area and encourages to } \\
\text { conduct externally funded research }\end{array}$ & .404 & & .379 & \\
\hline 26 & $\begin{array}{l}\text { The institution helps the faculty } \\
\text { researcher to gain seed money from } \\
\text { the concern funding agencies. }\end{array}$ & .370 & & & \\
\hline 2 & $\begin{array}{l}\text { A well-equipped digital library in the } \\
\text { institution provides the access to a } \\
\text { large repository of information \& } \\
\text { knowledge }\end{array}$ & & .745 & & \\
\hline 25 & $\begin{array}{l}\text { The institution provides a research } \\
\text { climate that maintains omniparitv } \\
\text { among researchers without any caste } \\
\text { or class or gender distinction. }\end{array}$ & & .720 & & \\
\hline 14 & $\begin{array}{l}\text { Institutions have a high h-index in } \\
\text { research publications. }\end{array}$ & & .681 & .422 & \\
\hline 1 & $\begin{array}{l}\text { Institution provides a separate list of } \\
\text { faculty publication bibliographies. }\end{array}$ & .307 & .550 & & \\
\hline 6 & $\begin{array}{l}\text { Inter- Institutional Research } \\
\text { collaborations and consortiums are } \\
\text { encouraged by the institution. }\end{array}$ & & .308 & & \\
\hline 10 & $\begin{array}{l}\text { Institution provides the free access of } \\
\text { research and plagiarism checking } \\
\text { software and allow free access to } \\
\text { research facilities without any time or } \\
\text { money constrains to researchers. }\end{array}$ & & & .716 & \\
\hline 13 & $\begin{array}{l}\text { Institution maintains a research } \\
\text { museum to create a showcase of } \\
\text { research to the public. }\end{array}$ & & & .675 & .349 \\
\hline 3 & $\begin{array}{l}\text { Laptops/ Computers are provided by } \\
\text { the institution for doing research. }\end{array}$ & & .367 & .695 & \\
\hline 4 & $\begin{array}{l}\text { Institution maintains books in the } \\
\text { library on the research areas of each } \\
\text { faculty. }\end{array}$ & & & .316 & \\
\hline 23 & $\begin{array}{l}\text { A well-furnished lab/research room } \\
\text { with research equipment is available } \\
\text { in the institution. }\end{array}$ & & & .319 & \\
\hline
\end{tabular}




\section{International Conference on Research in \\ BEHAVIORAL \& SOCIAL SCIENCES}

July $23-25,2021$

Stockholm, Sweden

\begin{tabular}{|c|c|c|c|c|c|}
\hline 7 & $\begin{array}{l}\text { Institution possesses a point-based } \\
\text { evaluation system to assess the quality } \\
\text { of research works. }\end{array}$ & & & .850 & \\
\hline 8 & $\begin{array}{l}\text { Institution showcases the research } \\
\text { output of the researchers. }\end{array}$ & & .349 & .684 & \\
\hline 5 & $\begin{array}{l}\text { Institution facilitates the inter- } \\
\text { disciplinary access of library to the } \\
\text { researchers without any cost. }\end{array}$ & .402 & & .541 & \\
\hline 11 & $\begin{array}{l}\text { Institution provides student-exchange } \\
\text { programmes. }\end{array}$ & & & .531 & \\
\hline 28 & $\begin{array}{l}\text { Institution maintains a Research } \\
\text { Advisory Committee to provide } \\
\text { fruitful suggestions to the researchers. }\end{array}$ & .359 & & & .718 \\
\hline 16 & $\begin{array}{l}\text { The institution gives priority to } \\
\text { research ethics. }\end{array}$ & .309 & & & .685 \\
\hline 17 & $\begin{array}{l}\text { The institution implements the } \\
\text { mentoring system for } \\
\text { Research aspirants. }\end{array}$ & .532 & & & .557 \\
\hline 12 & $\begin{array}{l}\text { Institution organises both virtual and } \\
\text { off-line expert classes in research } \\
\text { from foreign universities. }\end{array}$ & & & & .502 \\
\hline 15 & $\begin{array}{l}\text { The institution encourages the faculty } \\
\text { to be productive in research (eg. } \\
\text { Writing articles, books, and } \\
\text { conference papers). }\end{array}$ & & & & .381 \\
\hline 21 & $\begin{array}{l}\text { The institution organises research } \\
\text { forums which helps research scholars } \\
\text { to present their progress of their work } \\
\text { weekly. }\end{array}$ & & & & .344 \\
\hline 9 & $\begin{array}{l}\text { The institution motivates the scholars } \\
\text { and faculty by allowing them to come } \\
\text { up with innovative ideas in research. }\end{array}$ & & & .302 & .328 \\
\hline
\end{tabular}

Exploratory Factor analysis was conducted to reduce the components using principal component analysis. Integration of eigenvalue and scree plot results indicated that the measure represents five factors for assessing the institutional research culture. Table 3 shows the factor loading in institutional culture scale. Five predominant Institutional Research Culture components were selected based on eigen values which are greater than 0.30 . The values are greater than 0.3 , falling in the range 0.310 to 0.880 , suggesting that the data set was appropriate (Stewart 1981). The components explored are working conditions, research collaboration and sharing, research infrastructure, institutional policies and agenda and research mentoring and monitoring. Figure 1 represents the scree plot diagram. 


\section{$8^{\text {th }}$ International Conference on Research in}

\section{BEHAVIORAL \& SOCIAL SCIENCES}

July 23-25,2021 Stockholm, Sweden

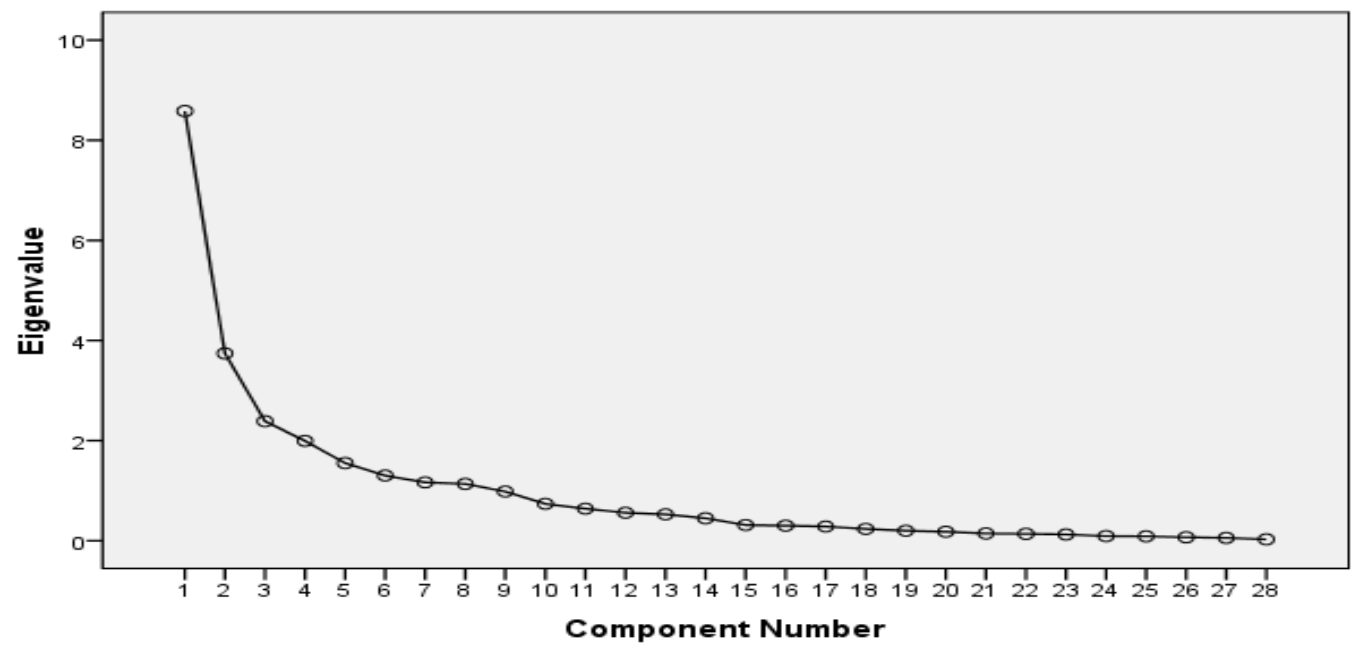

Table 4 represents the components of institutional research culture and question number of items that falls in each component.

Table 4: Dimension wise Question Numbers in Institutional Research Culture Scale

\begin{tabular}{lll} 
Sl.no. & Dimensions & $\begin{array}{l}\text { Question Numbers in Institutional Research } \\
\text { Culture Scale }\end{array}$ \\
\hline 1 & Working conditions & $18,19,20,22,24,26,27$ \\
\hline 2 & Research sharing and collaboration & $1,2,6,14,25$ \\
\hline 3 & Research infrastructure & $3,4,10,13,23$ \\
\hline 4 & Institutional policies and agenda & $5,7,8,11$ \\
\hline 5 & Research monitoring and mentoring & $9,12,15,16,17,21,28$ \\
\hline
\end{tabular}

After the factor loading, seven items were found to be under factor 1, five items correspondingly for factor 2 and 3, four items in factor 4 and finally seven items were fallen on factor 5. All the items loading in these 5 factors were in the acceptable level of factor loadings (i.e., loadings at or greater than .30). Strong evidence of reliability was indicated, with an acceptable level of Cronbach's alpha $(\alpha)=0.78$ (Cresswell, 2011). Given the factor loadings and the evidence of reliability, all 28 items were retained. All the items are found capable for assessing the institutional research culture.

\section{DISCUSSIONS}

This investigation of a well-substantiated measure of institutional research culture yielded promising initial results in terms of its psychometrics. Both reliability and validity indicators were strong, based on a geographically and academically diverse sample. Factor loadings supported Kahn and Miller's (2000) assertion that the items are relevant across a range of applied social and behavioural sciences. In line with Kahn and Miller (2000), the statistical analyses, that recommend keeping all 28 items as currently written in Table 3, to be further investigated, and recommend using only total IRCS scores. Of note, the sample was relatively moderate and predominately the 


\section{International Conference on Research in \\ BEHAVIORAL \& SOCIAL SCIENCES}

July $23-25,2021$

Stockholm, Sweden

faculty from female faculty, which may have limited the ability to find differences by gender as others have reported (Eagan \& Garvey, 2015; Fox \& Mohapatra, 2007). Confirmatory factor analysis (CFA) with larger samples also is needed.

The measure is relevant to the design and evaluation of research culture in institutions. First is the call to assess the scope of programs, and evaluations of them, to include consideration of contextual factors that influence the research culture (O'Sullivan \& Irby, 2011; Steinert, 2012). Second is the call to assess the present situation and add up the necessary elements to enhance the institutional research culture (Coetzee, 2019). The effectiveness of research culture in the institutions is deeply related with the research atmosphere of the institution especially the research infrastructure and the working conditions of the institutions. The present tool is effective to assess the research activities in the institution with the determined factors and assess the culture observed in the public university (Mendez \& Cruz, 2014).

Iqbal and Jalal (2018) reported that most of the institutional factors that can contribute to promoting research culture were not much favourable as perceived by faculty members. In a study conducted by Mirza, Qazi and Rawat (2012) about the prevalence of research culture in universities found that faculty members were lacking research skills, they conducted research activities only for research publications necessary for eligibility of higher positions. High teaching workload was assigned by the institution, which was a major hindrance in doing research. It was an indication of lack of institutional support for research and research culture. There was no provision of appropriate financial resources for research. The findings of present study reports to identify the factors for institutional support to enhance research culture in institutions.

The faculty and other higher governing bodies in the university can use the IRCS to identify the research culture of the institutions. It also used to conduct need assessments to identify what aspects of an institutional research culture need to be addressed and then conduct evaluations of the effectiveness of those programs. In the Indian context it is essential to identify the institutional research culture as it is a mandatory one to improve the overall quality of higher education institutions (University Grants Commission Report, 2019). The items in IRCS point to some key indicators that could be targeted in institutions. For example, institutional research policies, agenda and research collaboration are indispensable one in the institutions which can be easily assessed by the IRCS.

\section{CONCLUSION}

While reviewing literature, the researchers found that various factors such as institutional, working environment, research collaboration and financial factors (Clemena., \& Acosta, 2007; Cheeham, 2007; Mortimore, 2000) determines the institutional research culture. So, a standardised tool is essential based on the factors and were not prevalent at appropriate level in public sector universities especially in India (UGC Report, 2019). The present tool (IRCS) is developed based on all the mainstream factors that affect institutional research culture (Clemena \& Acosta, 20007). The faculty productivity tends to be tied to faculty success and the progress of quality in the institutions, it is important to begin exploring how institutions' research cultures hinder or support faculty members' scholarly productivity. The IRCS provides one new and promising avenue for assessing institutional research culture that can enhance the faculty members' research capacity and research climate which ultimately leads to the improvement in quality.

\section{Acknowledgment}




\title{
$8^{\text {th }}$ International Conference on Research in
}

\section{BEHAVIORAL \& SOCIAL SCIENCES}

July $23-25,2021$

\author{
Stockholm, Sweden
}

We acknowledge the financial assistance provided by Indian Council for Social Science Research (ICSSR), New Delhi under the fellowship grant id RFD/Short-Term/1920/GEN/EDU/34

\section{REFERENCES}

Ashok Mithra Commission. (1999). Report of the Kerala Education Commission. Kerala Shastra Sahithya Parishad.

Barrett, R. (2010). The Importance of Values in Building a High-Performance Culture. https://www.valuescentre.com/sites/default/files/uploads/20100706/The\%20Importance\% 20of50Values.pdf//

Cheetham, Andrew. (2007). Growing a Research Culture. Address to the Academic Senate, University of West Sydney. http//www.uws.edu.au//

Clemena, R. Marie., \& Acosta, Almonte. (2007). Developing Research Culture in Philippine Higher Education Institutions: Perspectives of University Faculty. $\mathrm{http} / / \mathrm{www}$.allbookez.com//

Coetzee, L. (2019). Framework for enhancing the research culture within the faculty of health sciences at the university of the free state. Doctoral Dissertation. University of Free State,

Creswell, J.W. (2005). Educational Research: Planning, Conducting and Evaluating Quantitative and Qualitative Research (2nd Ed.). Upper Saddle River, NJ: Merrill/Prentice Hall.

Draft Report of Kerala Perspective Plan. (2014). Government of Kerala. http//www.kerala.gov.in/docs/reports/vision2030/pdf

Eagan, M. K., Jr., \& Garvey, J. C. (2015). Stressing out: Connecting race, gender, and stress with faculty productivity. The Journal of Higher Education, 86, 923-951.

Fox, M. F., \& Mohapatra, S. (2007). Social-organizational characteristics of work and publication productivity among academic scientists in doctoral granting departments. The Journal of Higher Education, 78, 542-571.

Hair, J. F., Black, W. C., Babin, B. J., \& Anderson, R. E. (2010). Multivariate data analysis (7th ed.). Upper Saddle River, NJ: Pearson.

Hanover-Research. (2014). Research Themes in Higher Education. http://www.hanoverreserach.com//

Hazelcorn, E. (2005). University Research Management: Developing Research in New Institutions. OECD.

Hill, Robin. (1999, July). Revisiting the term Research Culture. Paper presented at HERDSA Annual International Conference, Melbourne. 


\section{$8^{\text {th }}$ International Conference on Research in}

\section{BEHAVIORAL \& SOCIAL SCIENCES}

July $23-25,2021$

Stockholm, Sweden

Iqbal, Muhammad., \& Samreen, Jalal. (2018). Factors Influencing Research Culture in Public Universities of Punjab: Faculty Members' Perspective. Bulletin of Education and Research, 40 (3), 187-200.

Kahn, J. H. (2001). Predicting the scholarly activity of counselling psychology students: A refinement and extension. Journal of Counselling Psychology, 48, 344-354.

Kahn, J. H., \& Miller, S. A. (2000). Measuring global perceptions of the Research Training Environment using a short form of the RTES-R. Measurement and Evaluation in Counselling and Development, 33, 103-199.

Kaiser, H.F., \& Rais, J. (1974). Mark IV. Educational and Psychological Measurement, 34 111-117.

Lewis, J. (1997). India's Political Economy: Governance and Reform. Oxford University Press.

Mendez, E.H., \& Cruz, M.R. (2014). Research Culture in Higher Education: The Case of a Foreign Language Department in Mexico. Profile 16 (2), 135-150.

MHRD. (2018). Educational statistics of MHRD. Ministry of Higher Education.

Ministry of Human Resources and Development. (2011). Annual Report. New Delhi: Govt. of India.

Mirza, N., Qazi, W., \& Rawat, K. J. (2012). Research culture in teacher education: A study of perception of university teacher educators in Pakistan. European Journal of Social Sciences, 28(4), 559-68. http://www.europeanjournalofsocialsciences//

Mortimore, Peter. (2000). Does Educational Research Matter? British Education Research Journal, 26 (1), 5-24.

Mortimore, Peter. (2000). Does Educational Research Matter? British Education Research Journal, 26 (1), 5-24.

Mvududu, N. H., \& Sink, C. (2013). Factor analysis in counselling research and practice. Counselling Outcome Research and Evaluation, 4, 75-98.

O’Sullivan, P. S., \& Irby, D. M. (2011). Reframing research on faculty development. Academic Medicine, 86, 421-428.

Perkins, J. A. (1988, September 25). Stafford Little Lectures at Princeton. New York Times. Retrieved from http//www.bartleby.com//

Steinert, Y. (2012). Perspectives on faculty development: Aiming for 6/6 by 2020. Perspectives on Medical Education, 1(1), 31-42.

University Grants Commission Report. (2019). UGC. Ministry of Higher Education.

University Grants Commission. (2008). Issues related to Expansion, Inclusiveness, Quality and Finance. Ministry of Higher Education. 
$8^{\text {th }}$ International Conference on Research in

\section{BEHAVIORAL \& SOCIAL SCIENCES}

Stockholm, Sweden

University Grants Commission. (2012). Annual Report (2012 - 2013). Ministry of Higher Education. 